\title{
Low- to high-density lipoprotein cholesterol ratio followed by coronary computed tomography angiography improves coronary plaque classification accuracy
}

\author{
Xiyang Hu${ }^{1}$, Wei Zhang ${ }^{2}$, Nairui Zhao ${ }^{3}$, Rongcheng $\mathrm{Zhao}^{4}$ and Shuofeng $\mathrm{Li}^{1}$ \\ ${ }^{1}$ Department of Radiology, Cangzhou Central Hospital, Hebei, 061000, Cangzhou, China \\ ${ }^{2}$ Department of Radiology, Cangzhou Hospital of Integrated Traditional and Western Medicine, Hebei, 061000, Cangzhou, China \\ ${ }^{3}$ Department of Endocrinology, Cangzhou Central Hospital, Hebei, 061000, Cangzhou, China \\ ${ }^{4}$ Department of Cardiology, Cangzhou Central Hospital, Hebei, 061000, Cangzhou, China \\ Correspondence to: Xiyang Hu, email: xiyanghhhh@163.com
}

Keywords: noncalcified plaque; mixed plaque; coronary computed tomography angiography; low-to high-density lipoprotein cholesterol ratio; intravascular ultrasound

Received: August 08, 2017

Accepted: November 16, 2017

Published: December 21, 2017

Copyright: $\mathrm{Hu}$ et al. This is an open-access article distributed under the terms of the Creative Commons Attribution License 3.0 (CC BY 3.0), which permits unrestricted use, distribution, and reproduction in any medium, provided the original author and source are credited.

\section{ABSTRACT}

Coronary computed tomography angiography (CCTA) is a noninvasive test for detection and analysis of coronary plaques morphology and classification. The low- to high-density lipoprotein cholesterol $(\mathrm{L} / \mathrm{H})$ ratio is associated with plaques vulnerability. The study aims to investigate the diagnostic accuracy of CCTA and L/H ratio for plaques classification. We enrolled 212 patients with coronary artery single-vessel disease who performed preoperative CCTA and Intravascular ultrasound (IVUS)-guided invasive coronary angiography. Patients were assigned to the acute coronary syndrome (ACS) group $(n=129)$ and stable angina pectoris (SAP) group $(n=83)$. CCTA showed that patients with ACS had more soft plaque and less calcific plaque than those with SAP. The plaque volume and remodeling index measured by CCTA showed good correlation with those measured by IVUS. IVUS identified 91 soft, 58 mixed and 63 calcific plaques in this cohort. For diagnosis of noncalcified plaque (soft and mixed), CCTA had the sensitivity and specificity of $87.9 \%$ and $90.4 \%$, respectively. While refer to the further diagnosis of mixed plaque from noncalcified plaque, the sensitivity and specificity was $\mathbf{8 8 . 4 \%}$ and $\mathbf{8 8 . 8 \%}$, respectively. The $\mathrm{L} / \mathrm{H}$ ratio was gradually decreased from soft plaque to calcific plaque. If the patients had both the two characteristics (L/H $\geq 2.55$ and CCTA), the sensitivity, and specificity were improved in diagnosing noncalcified plaque or mixed plaque. In conclusion, a combined application of CCTA and L/H ratio improves the diagnostic accuracy for coronary noncalcified plaque or mixed plaque as compared to CCTA along.

\section{INTRODUCTION}

Major adverse cardiovascular events are often the initial manifestation of coronary artery disease (CAD), which is related mostly to one pathophysiologic substrate: the rupture or erosion of a vulnerable plaque [1]. Intravascular ultrasound (IVUS) is capable of cross-sectional imaging of coronary arteries and a comprehensive assessment of coronary atherosclerotic plaques. However, due to its invasiveness, the related increased risk during the procedure, and high cost, IVUS cannot be used for routine evaluation of plaque characteristics [2]. Meanwhile, recent improvements in computed tomography (CT) technology and the advent of the multislice CT have spurred interest in noninvasive detection of morphologic characteristics of coronary plaques using coronary CT angiography (CCTA). Identification of noncalcified plaques, particularly mixed plaques, has been considered as important features of plaque vulnerability and instability [3-5]. Plenty 
of studies have shown CCTA is capable to identify several morphologic and geometric characteristics of atherosclerotic plaques and demonstrated a good correlation between plaque composition derived from CCTA and IVUS [6-8]. Nevertheless, for diagnosis of noncalcified plaque, CCTA has relative low sensitivity and specificity than calcified plaques [9] because of the substantial overlap of the density values between lipid-rich and fibrous plaques [10].

Since biomarkers are proposed for risk stratification due to their relative ease of use, high-sensitivity cardiac troponin T (hs-cTnT) [11-13], NT-proBNP [14], Cystatin C [15], serum matrix metalloproteinase-9 [16], and lipoproteinassociated phospholipase A2 [17] have been considered closely related with coronary plaque morphology. Of note, a recent study revealed that the low-density lipoproteincholesterol/high-density lipoprotein-cholesterol (L/H) ratio independently had a significant fixed effect with the percentage of the lipid component of coronary plaques [18] and a high $\mathrm{L} / \mathrm{H}$ ratio was reported closely associated with larger numbers of low density noncalcified plaque [19]. Hence, there are expectations that with the assistance of $\mathrm{L} / \mathrm{H}$ ratio, the diagnostic accuracy for noncalcified plaque (especially the mixed one) in patients with CAD of CCTA would significant increase. On above data, the aim of our study was to assess the diagnostic performance of CCTA and $\mathrm{L} / \mathrm{H}$ ratio by using invasive IVUS as the reference standard.

\section{RESULTS}

\section{Clinical characteristics and laboratory results of study subjects}

The procedures followed in this study were depicted in Figure 1. The final 212 participants that enrolled in this study comprised 119 men and 93 women with a mean age of 54.3 \pm 11.9 years. As shown in Table 1 , there was no statistical differences between ACS and SAP group when comparing to the age, sex, BMI, current smoking, hypertension and diabetes mellitus. The level of hs-cTn T and NT-proBNP were significant higher in the ACS group when compared to the SAP group $(P<0.05)$. Use of beta-blockers, ACEI/ARB, calcium channel blocker, diuretic and statins were equal between the two groups. Although no significant differences were observed in HDL-C or LDL-C levels between groups, $\mathrm{L} / \mathrm{H}$ ratio differed significantly between two groups $(P<$ 0.001). We also identified that patients with ACS had higher levels of creatinine, hs-CRP and Hcy than those with SAP $(P<0.05$ for all $)$.

\section{CCTA and IVUS characteristics of coronary plaques}

The culprit lesion of each subject was determined during ICA. Coronary angiography revealed 212 lesions, containing 159 Left anterior descending artery (LAD,
75\%), 20 Left circumflex artery (LCX, 9.4\%), and 33 Right coronary artery (RCA,15.6\%). As illustrated in Table 2, lesion length, calcium score, vessel volume, lumen volume and minimum lumen area (MLA), showed no significant differences between two groups $(P>0.05$ for all). CCTA showed that although, plaque volume was higher in the ACS group than in the SAP group, no significant difference was observed $(P=0.083)$. In addition, noncalcified plaque volume and plaque burden were significant higher, while the remodeling index was lower in ACS group than that in SAP group (126 \pm 78.3 vs. $101 \pm 66.1 \mathrm{~mm}^{3}, P=0.017 ; 72.7 \pm 9.88$ vs. $68.3 \pm$ $8.35, P=0.001 ; 1.05 \pm 0.36$ vs. $1.31 \pm 0.49, P<0.001)$. Plaques were defined as soft $(n=82)$, mixed $(n=55)$ and calcific $(n=75)$ according to the CCTA findings. Patients in ACS group owned more soft plaque and less calcific plaque than those with $\operatorname{SAP}(P=0.030)$.

\section{The accuracy of CCTA in evaluating plaque characteristic}

The mean plaque volume detected by IVUS were $155 \pm 119 \mathrm{~mm}^{3}$. Pearson's correlation coefficient was $\mathrm{r}=0.8926(P<0.001)$ when analyzed the correlation of plaque volume derived from CCTA and IVUS (Figure 2A). In the 212 lesions investigated by CCTA and IVUS, the mean Remodeling Index was $1.22 \pm 0.46$ in CCTA and $1.27 \pm 0.35$ in IVUS $(r=0.8472, P<0.001$, Figure 2B). IVUS identified 91 soft, 58 mixed and 63 calcific plaque in total. The plaque subtypes classified by CCTA gave close agreement with that evaluated by IVUS (Table 3 ). In general, the plaque subtypes were misclassified by 128-slice CT in 39 of 212 atherosclerotic lesions. For diagnosis of noncalcified plaque (soft and mixed), the sensitivity, specificity, positive predictive value (PPV) and negative predictive value (NPV) was $87.9 \%, 90.4 \%$, $95.5 \%$ and $76.0 \%$, respectively. While refer to the further diagnosis of mixed plaque from noncalcified plaque, the sensitivity, specificity, PPV and NPV was $88.4 \%, 88.8 \%$, $83.8 \%$ and $80.0 \%$, respectively (Table 4 ). Examples of CCTA plaque types and corresponding IVUS imaging are presented in Figures 3-5.

\section{Association of $\mathrm{L} / \mathrm{H}$ ratio with the characteristics of coronary plaque}

As CCTA had a relative low power to identified noncalcified plaque, we further compared the expression levels of laboratory values between different plaque subtypes, in order to provide cool idea to improve the diagnostic value of CCTA. Unexpected, Table 5 showed that the levels of hs-cTn T and LDL-C differed in plaque classification and $\mathrm{L} / \mathrm{H}$ ratio showed the most change among groups $(P<0.001)$. Thereby, we investigate the different clinical parameter between groups with high or low $\mathrm{L} / \mathrm{H}$ ratio. We found that patients with $\mathrm{L} / \mathrm{H} \geq 2.55$ 
Table 1: Demographic, clinical characteristics and laboratory results of the study groups

\begin{tabular}{|c|c|c|c|}
\hline Clinical Characteristics & $\begin{array}{l}\text { ACS group } \\
(n=129)\end{array}$ & $\begin{array}{l}\text { SAP group } \\
\quad(n=83)\end{array}$ & $P$ value \\
\hline Age (years) & $54.2 \pm 12.1$ & $55.4 \pm 10.8$ & 0.463 \\
\hline Male (n, \%) & $77(59.7)$ & $42(50.6)$ & 0.246 \\
\hline BMI $(\mathrm{kg} / \mathrm{m} 2)$ & $28.1 \pm 3.70$ & $27.6 \pm 4.41$ & 0.374 \\
\hline Current smoking $(n, \%)$ & $62(48.1)$ & $33(39.8)$ & 0.296 \\
\hline Hypertension $(n, \%)$ & $80(62.0)$ & $43(51.8)$ & 0.184 \\
\hline Diabetes mellitus $(n, \%)$ & $64(49.6)$ & $37(44.6)$ & 0.565 \\
\hline \multicolumn{4}{|l|}{ Medications } \\
\hline Beta-blockers & $90(69.8)$ & $59(71.1)$ & 0.792 \\
\hline ACEI/ARB & $112(86.8)$ & $73(88.0)$ & 0.976 \\
\hline Calcium channel blocker & $42(32.6)$ & $30(36.1)$ & 0.697 \\
\hline Diuretic & $68(52.7)$ & $37(44.6)$ & 0.310 \\
\hline Statins & $118(91.5)$ & $71(85.5)$ & 0.259 \\
\hline \multicolumn{4}{|l|}{ Laboratory tests } \\
\hline Hs-cTn T (ng/L) & $7.80 \pm 3.26$ & $4.43 \pm 2.91$ & $<0.001$ \\
\hline D-dimer $(\mu \mathrm{g} / \mathrm{mL})$ & $3.41 \pm 1.77$ & $3.12 \pm 1.69$ & 0.237 \\
\hline NT-proBNP (pg/ml) & $283 \pm 180$ & $232 \pm 119$ & 0.024 \\
\hline Triglyceride (mg/dl) & $1.67 \pm 0.73$ & $1.56 \pm 0.46$ & 0.222 \\
\hline HDL-C (mmol/L) & $1.19 \pm 0.37$ & $1.31 \pm 0.49$ & 0.058 \\
\hline LDL-C (mmol/L) & $3.17 \pm 1.38$ & $2.89 \pm 0.92$ & 0.077 \\
\hline $\mathrm{L} / \mathrm{H}$ ratio & $2.53 \pm 0.63$ & $2.21 \pm 0.54$ & $<0.001$ \\
\hline $\mathrm{HbA1c}(\%)$ & $6.13 \pm 1.39$ & $5.83 \pm 0.91$ & 0.083 \\
\hline $\operatorname{Scr}(\mu \mathrm{mol} / \mathrm{L})$ & $79.1 \pm 18.3$ & $72.5 \pm 13.5$ & 0.005 \\
\hline Hs-CRP (mg/L) & $5.81 \pm 2.12$ & $3.93 \pm 1.87$ & $<0.001$ \\
\hline Hcy $(\mu \mathrm{mol} / \mathrm{L})$ & $11.2 \pm 5.65$ & $7.69 \pm 3.73$ & $<0.001$ \\
\hline
\end{tabular}

Note: BMI = body mass index; hs-cTn T = high sensitive cardiac Troponin T; HDL-C = high-density lipoprotein cholesterol; LDL-C = low-density lipoprotein cholesterol; L/H=LDL-C/HDL-C; Scr = Serum creatinine; Hs-CRP = high-sensitivity C-reactive protein; Hcy = homocysteine.

were older and had higher BMI, compared to those with $\mathrm{L} / \mathrm{H}<2.55$ (Table 6). Subsequent multivariate regression analyses revealed that independent predictors of $\mathrm{L} / \mathrm{H}$ $\geq 2.55$ were age $(\beta=1.019,95 \%$ CI: $0.012-2.239, p=$ $0.044)$, BMI $(\beta=1.158,95 \%$ CI: 0.144 to $4.903, p=$ $0.022)$, and Hcy $(\beta=1.428,95 \%$ CI: $0.107-4.748, p=$ 0.010) (Table 7).

\section{Diagnostic value for coronary plaque subtypes by combining CCTA, and $\mathrm{L} / \mathrm{H}$ ratio}

The sensitivity and specificity would be $89.9 \%$ and $79.3 \%$ when $\mathrm{L} / \mathrm{H}$ alone was used to identify noncalcified plaque. Interesting, when combining with CCTA, the sensitivity, specificity, PPV and NPV increased to $95.9 \%$, $93.6 \%, 97.3 \%$ and $90.8 \%$ for diagnosing noncalcified plaque respectively. Moreover, if $\mathrm{L} / \mathrm{H}$ ratio was used to recognize mixed plaque from noncalcified plaque, the sensitivity, specificity, PPV and NPV would be $86.0 \%$,
$91.7 \%, 94.8 \%$ and $78.6 \%$. If the patients had both the two characteristics ( $\mathrm{L} / \mathrm{H} \geq 2.55$ with CCTA), the sensitivity, specificity, PPV and NPV would be $92.1 \%, 94.4 \%, 96.5 \%$ and $87.9 \%$ for diagnosis of mixed plaque respectively. All the sensitivity, specificity, PPV, NPV for plaque classification according to the $\mathrm{L} / \mathrm{H}$ ratio and CCTA were shown in Table 8.

\section{DISCUSSION}

The accurate characterisation of coronary atherosclerotic plaques remains challenging. Limited spatial and contrast resolutions of most clinical imaging techniques prevent classifications that exactly match histology. Currently, classifications provided by IVUS or optical coherence tomography are probably the closest to histopathology $[20,21]$. We assessed the diagnostic performance of CCTA or $\mathrm{L} / \mathrm{H}$ ratio or both, comparison with IVUS in the current study. The detection of mixed 
Table 2: CCTA measures characteristics

\begin{tabular}{lccc}
\hline \multicolumn{1}{c}{ CCTA Parameter } & ACS group $(\boldsymbol{n}=\mathbf{1 2 9})$ & SAP group $(\boldsymbol{n}=\mathbf{8 3})$ & $\boldsymbol{P}$ values \\
\hline Lesion length, mm & $16.5 \pm 12.0$ & $18.5 \pm 12.6$ & 0.247 \\
Calcium score & $390(107-975)$ & $311(115-723)$ & 0.410 \\
Vessel volume (mm3) & $406 \pm 255$ & $396 \pm 227$ & 0.772 \\
Plaque volume (mm3) & $169 \pm 107$ & $144 \pm 93.6$ & 0.083 \\
NCPV (mm3) & $126 \pm 78.3$ & $101 \pm 66.1$ & 0.017 \\
Lumen volume (mm3) & $237 \pm 133$ & $252 \pm 149$ & 0.446 \\
MLA (mm2) & $2.51 \pm 1.70$ & $2.96 \pm 1.72$ & 0.063 \\
Plaque burden (\%) & $72.7 \pm 9.88$ & $68.3 \pm 8.35$ & 0.001 \\
Remodeling index & $1.05 \pm 0.36$ & $1.31 \pm 0.49$ & $<0.001$ \\
Plaque morphology* & & & 0.030 \\
Soft $(n=82)$ & $53(41.1)$ & $29(34.9)$ & \\
Mixed $(n=55)$ & $39(30.2)$ & $16(19.3)$ & \\
Calcific $(n=75)$ & $37(28.7)$ & $38(45.8)$ & \\
\hline
\end{tabular}

Note: $\mathrm{NCPV}=$ noncalcified plaque volume; MLA $=$ minimum lumen area. ${ }^{*}$ obtained from CCTA.

Table 3: Consensus table of 128-slice CT and IVUS to detect and classify coronary plaques

\begin{tabular}{lccc}
\hline & & IVUS & Calcific \\
\hline 128-slice CT & Soft & Mixed & 1 \\
Soft & 76 & 5 & 5 \\
Mixed & 10 & 40 & 57 \\
Calcific & 5 & 13 & \\
\hline
\end{tabular}

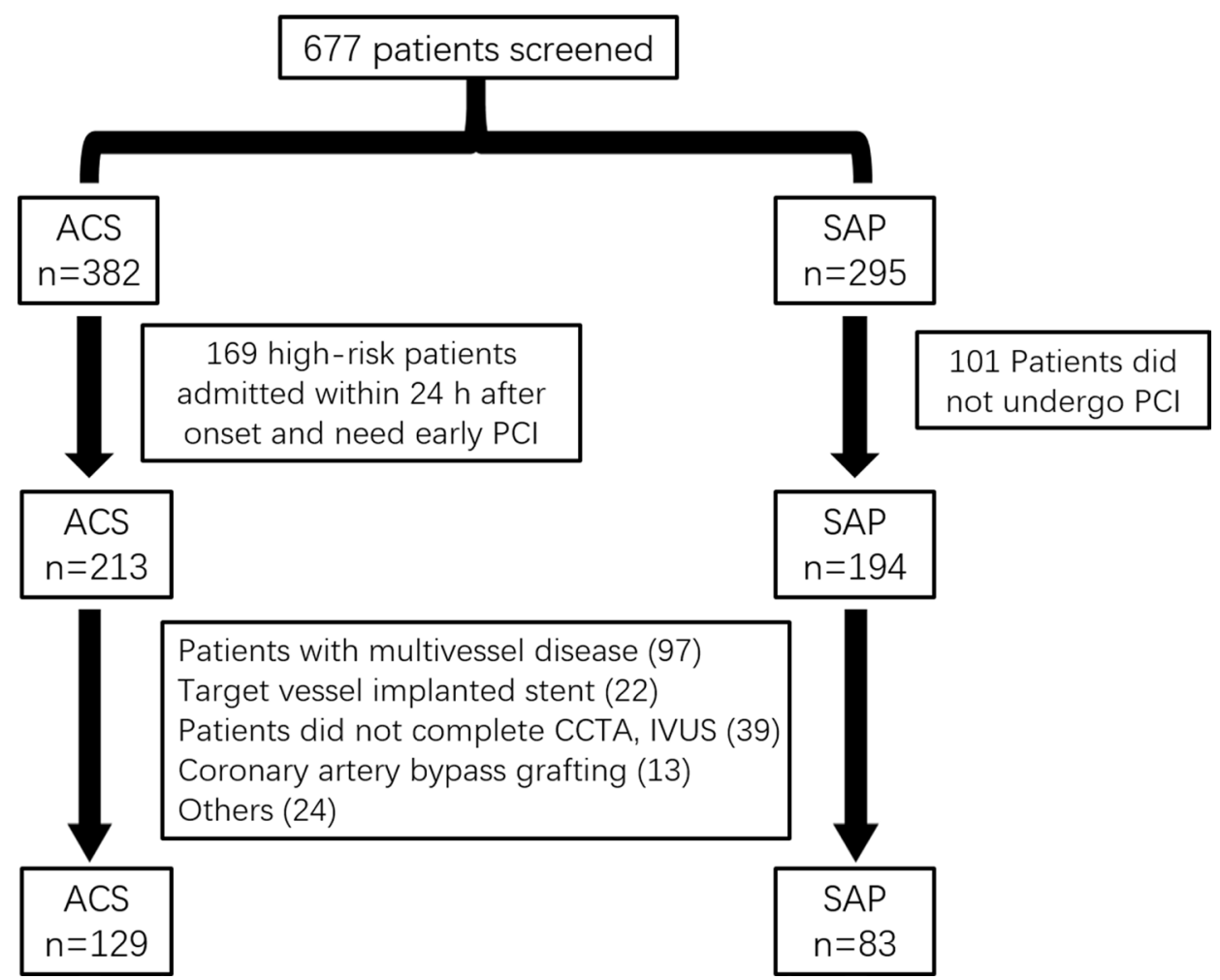

Figure 1: Flow diagram of the phases of the study. 
Table 4: Diagnostic accuracy data for CCTA in detecting coronary plaque

\begin{tabular}{llllll}
\hline & Sensitivity (\%) & Specificity (\%) & $\begin{array}{l}\text { Positive } \\
\text { Predictive } \\
\text { Value (\%) }\end{array}$ & $\begin{array}{l}\text { Negative } \\
\text { Predictive } \\
\text { Value (\%) }\end{array}$ & Accuracy (\%) \\
\hline Noncalcified & 87.9 & 90.4 & 95.5 & 76.0 & 88.7 \\
mixed & 88.4 & 88.8 & 83.8 & 80.0 & 88.5 \\
\hline
\end{tabular}

Note: noncalcified included soft and mixed plaque.

Table 5: The comparison analysis of various serum biomarkers in different classified plaques

\begin{tabular}{lllll}
\hline Biomarkers & Soft $(\boldsymbol{n}=\mathbf{9 1})$ & Mixed $(\boldsymbol{n}=\mathbf{5 8})$ & Calcific $(\boldsymbol{n}=\mathbf{6 3})$ & $\boldsymbol{P}$ value \\
\hline hs-cTn T $(\mathrm{ng} / \mathrm{L})$ & $6.37 \pm 3.25$ & $5.77 \pm 2.67$ & $4.73 \pm 2.41^{*}$ & 0.003 \\
D-dimer $(\mu \mathrm{g} / \mathrm{mL})$ & $3.14 \pm 1.55$ & $3.27 \pm 1.32$ & $3.66 \pm 1.80$ & 0.126 \\
NT-proBNP $(\mathrm{pg} / \mathrm{ml})$ & $271 \pm 197$ & $246 \pm 141$ & $229 \pm 129$ & 0.287 \\
HDL-C $(\mathrm{mmol} / \mathrm{L})$ & $1.20 \pm 0.34$ & $1.26 \pm 0.37$ & $1.12 \pm 0.29$ & 0.068 \\
LDL-C $(\mathrm{mmol} / \mathrm{L})$ & $3.20 \pm 1.58$ & $2.82 \pm 1.32$ & $2.60 \pm 1.12^{*}$ & 0.027 \\
L/H ratio & $2.78 \pm 0.56$ & $2.45 \pm 0.60^{*}$ & $2.39 \pm 0.71^{\#^{*}}$ & $<0.001$ \\
Scr $(\mu \mathrm{mol} / \mathrm{L})$ & $71.8 \pm 13.9$ & $73.6 \pm 14.2$ & $75.4 \pm 17.5$ & 0.351 \\
Hs-CRP $(\mathrm{mg} / \mathrm{L})$ & $5.06 \pm 2.47$ & $4.89 \pm 1.72$ & $4.33 \pm 2.07$ & 0.115 \\
Hcy $(\mu \mathrm{mol} / \mathrm{L})$ & $10.3 \pm 3.28$ & $9.73 \pm 4.63$ & $8.92 \pm 4.16$ & 0.109 \\
\hline
\end{tabular}

Note: hs-cTn T = high sensitive cardiac Troponin T; HDL-C = high-density lipoprotein cholesterol; LDL-C = low-density lipoprotein cholesterol; L/H = LDL-C/HDL-C; Scr = Serum creatinine; Hs-CRP = high-sensitivity C-reactive protein; Hcy $=$ homocysteine ${ }^{*} P<0.05$ vs. Soft group, ${ }^{\#} P<0.05$ vs. Mixed group obtained from one-way ANOVA followed by least significant difference (LSD) multiple comparison test.

plaque is of potential relevance owing to their propensity to rupture and cause future cardiac events [22]. The noncalcified plaques, thereby, were further divide into soft and mixed plaques in the present study because thin-cap fibroatheromas were most prevalent in mixed plaques [8].

To confirm the accuracy of 128-slice CT in evaluating plaque morphology, we found plaque volume and remodeling index measured by CCTA were accurate when compared with those measured by IVUS, which was similar with previous studies $[6,23]$. We then compared to quantitative functional markers derived from CT and IVUS and found good correlation in plaque volume and remolding index. This phenomenon was also observed in the studies by Achenbach et al. [6] and Voros et al. [24] We identified 63 calcific plaque and 149 noncalcified plaques using IVUS in our cohort. When using contrast enhanced 128 -slice CT, the accuracy was $88.7 \%$, and the sensitivity and specificity was $87.9 \%$ and $90.4 \%$. The results were
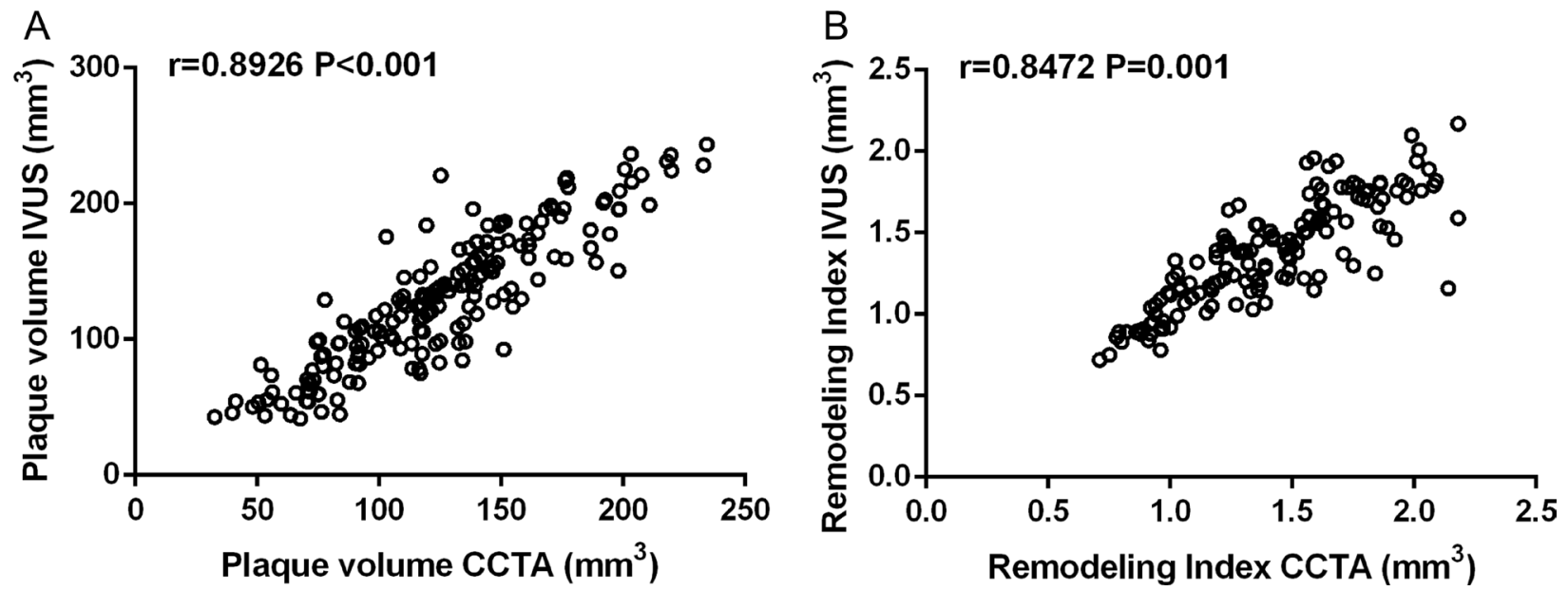

Figure 2: (A) Univariate linear correlation analysis showed the correlation of plaque volume in intravascular ultrasound (IVUS) and coronary computed tomography angiography (CCTA) $(n=212, \mathrm{r}=0.8926, P<0.001)$. (B) Correlation of remodeling index in IVUS and $\operatorname{CCTA}(n=212, \mathrm{r}=0.8472, P<0.001)$. 
Table 6: Patient characteristics stratified by $\mathrm{L} / \mathrm{H}$ ratio

\begin{tabular}{|c|c|c|c|}
\hline Parameter & $\mathrm{L} / \mathrm{H}<2.55 n=89$ & $\mathrm{~L} / \mathrm{H} \geq 2.55 n=123$ & $P$ values \\
\hline Age (years) & $52.1 \pm 9.5$ & $54.9 \pm 10.2$ & 0.043 \\
\hline Male $(n, \%)$ & $48(53.9)$ & $79(64.2)$ & 0.172 \\
\hline BMI $(\mathrm{kg} / \mathrm{m} 2)$ & $26.9 \pm 3.75$ & $28.2 \pm 3.96$ & 0.017 \\
\hline Hypertension $(n, \%)$ & $54(60.7)$ & $69(56.1)$ & 0.599 \\
\hline Diabetes mellitus $(n, \%)$ & $36(40.4)$ & $63(51.2)$ & 0.158 \\
\hline Hyperlipidemia $(n, \%)$ & $49(55.1)$ & $73(59.3)$ & 0.183 \\
\hline $\operatorname{ACS}(n, \%)$ & $51(57.3)$ & $78(63.4)$ & 0.099 \\
\hline STEMI & $15(16.9)$ & $28(22.8)$ & \\
\hline NSTEMI & $24(26.9)$ & $36(29.2)$ & \\
\hline Unstable Angina & $12(13.5)$ & $14(11.4)$ & \\
\hline
\end{tabular}

Note: HDL-C = high-density lipoprotein cholesterol; LDL-C = low-density lipoprotein cholesterol; L/H = LDL-C/HDL-C; $\mathrm{BMI}=$ body mass index; ACS = acute coronary syndrome; STEMI = ST segment elevation myocardial infarction; NSTEMI $=$ non-ST segment elevation myocardial infarction.

Table 7: Multivariate linear regression analyses between $\mathrm{L} / \mathrm{H}$ ratio and clinical parameters

\begin{tabular}{lccc}
\hline \multicolumn{1}{c}{ Marker } & $\begin{array}{c}\text { Standardized correlation } \\
\text { coefficient }\end{array}$ & $\mathbf{9 5 \% C I}$ & $\boldsymbol{P}$ \\
\hline Age $($ years $)$ & 1.019 & $0.012,2.239$ & 0.044 \\
BMI $\left(\mathrm{kg} / \mathrm{m}^{2}\right)$ & 1.158 & $0.144,4.903$ & 0.022 \\
Hypertension & -0.967 & $-1.145,3.149$ & 0.208 \\
Diabetes mellitus & 1.157 & $-0.546,2.986$ & 0.349 \\
Triglyceride $(\mathrm{mg} / \mathrm{dl})$ & 0.045 & $-0.031,0.248$ & 0.133 \\
HbAlc $(\%)$ & 0.038 & $-0.014,0.188$ & 0.405 \\
Scr $(\mu \mathrm{mol} / \mathrm{L})$ & -1.417 & $-3.127,4.506$ & 0.551 \\
Hs-CRP $(\mathrm{mg} / \mathrm{L})$ & 0.088 & $-0.002,0.175$ & 0.069 \\
Hcy $(\mu \mathrm{mol} / \mathrm{L})$ & 1.428 & $0.107,4.748$ & 0.010 \\
\hline
\end{tabular}

Note: $\mathrm{CI}$ = confidence interval; $\mathrm{Scr}=$ Serum creatinine; Hs-CRP = high-sensitivity C-reactive protein; Hcy = homocysteine.

similar with a meta-analysis by Gao et al. that CT has higher diagnostic sensitivity and specificity for calcified plaques $(93 \%$ and $98 \%)$ than noncalcified plaques $(88 \%$ and $92 \%$ ) [25]. CT is known for its ability to show calcifications, but visualization of intraplaque hemorrhage (homogeneous plaques without calcification are stable fibrous plaques) is difficult [26]. For distinguishing soft and mixed plaque, the results are also not promising resulting from significant overlap in attenuation values between individual plaques [23, 25, 27]. The sensitivity and specificity was $88.4 \%$ and $88.8 \%$, respectively in this study for diagnosing mixed plaques.

Although CCTA offers an interesting option to noninvasively detect, quantify and characterize coronary plaque, the above diagnostic accuracy is not sufficient for clinical application. So far, variety of risk factors, such as hypertension, diabetes, smoking and dyslipidemia are strongly associated with the development of CAD [28]. $\mathrm{L} / \mathrm{H}$ ratio, rather than individual assessment of LDL-C and
HDL-C, is more closely associated with the development of CAD [29] and accordingly, we also found age, BMI and the levels of Hcy had correlation with $\mathrm{L} / \mathrm{H}$ ratio in patients with ACS and SAP. In addition, it is receiving considerable attention as a new risk factor for coronary plaque vulnerability. A meta-analysis suggested that a decrease of $\mathrm{L} / \mathrm{H}$ ratio after statin treatment was significant associated with regression of the atheroma volume [30]. In the current study, we found $\mathrm{L} / \mathrm{H}$ ratio differed significantly between different plaque type determined by IVUS. The ratio was highest in the soft plaque and lowest in the calcific plaque. These results may be explained by a study about evaluation the lipid component of non-culprit lesions that the $\mathrm{L} / \mathrm{H}$ ratio was the most relevant parameter in predicting the lipid component of coronary plaques [18], as the lipid component is gradually decreased from soft plaque to calcific plaque. Another study also identified that high $\mathrm{L} / \mathrm{H}$ ratio was associated with a high percentage of lipid volume and a low percentage of fibrous 
Table 8: Diagnostic value for coronary plaque subtypes by combining CCTA, and L /H

\begin{tabular}{lccccc}
\hline \multicolumn{1}{c}{ Category } & $\begin{array}{c}\text { Sensitivity } \\
(\%)\end{array}$ & $\begin{array}{c}\text { Specificity } \\
(\%)\end{array}$ & $\begin{array}{c}\text { Positive } \\
\text { Predictive } \\
\text { Value (\%) }\end{array}$ & $\begin{array}{c}\text { Negative } \\
\text { Predictive } \\
\text { Value (\%) }\end{array}$ & $\begin{array}{c}\text { Accuracy } \\
(\%)\end{array}$ \\
\hline Noncalcified plaque & & & & & \\
L/H ratio & 89.9 & 79.3 & 91.2 & 76.9 & 86.8 \\
CCTA + L/H ratio & 95.9 & 93.6 & 97.3 & 90.8 & 95.3 \\
Mixed plaque & & & & & \\
L/H ratio & 86.0 & 91.7 & 94.8 & 78.6 & 88.1 \\
CCTA + L/H ratio & 92.1 & 94.4 & 96.5 & 87.9 & 93.0 \\
\hline
\end{tabular}

Note: noncalcified included soft and mixed plaque.

volume in left main coronary artery lesions [31]. Besides, investigators found an inverse correlation between LDL-C level and the minimum plaque CT density. An $\mathrm{L} / \mathrm{H}>2.5$ could predict low-density plaques (OR 2.39, 95\%CI: 1.28-4.86) [19]. And similarly, a high L/H ratio was a useful marker for unstable plaques in patients with SAP [32]. We for the first time identified the $\mathrm{L} / \mathrm{H}$ $\geq 2.55$ enables characterization of mixed plaque with an acceptable sensitivity (86.0\%) and specificity (91.7\%) both in patient with ACS and SAP. These finding triggered us to combined it with CCTA to improve the diagnostic accuracy. A combination of $\mathrm{L} / \mathrm{H} \geq 2.55$ and $\mathrm{CCTA}$ yield an excellent sensitivity and PPV for diagnosing noncalcified plaque and a high specificity and PPV for mixed plaque. Based on the foregoing data, we conclude that the joint application of $\mathrm{L} / \mathrm{H}$ ratio and CCTA is useful in classifying coronary plaque types. It is no doubt that $\mathrm{L} / \mathrm{H}$ could not replace the imaging tools for identification plaque types, but may act as a complementary method. Improvement in imaging techniques may take years, but this is really an easy obtained biomarker.

Certain limitations of our study should be mentioned. Firstly, we could not analyze L/H ratio in subgroup with normal, low or high HDL-C levels, which may lead to the overestimate of its diagnostic accuracy. Some patients with genetically induced low levels of HDL-C may also influence $\mathrm{L} / \mathrm{H}$ ratio. As statins treatment could decrease plaque volume [33] and L/H ratio [34], whether the change of $\mathrm{L} / \mathrm{H}$ ratio during the lipid-lowering therapy could greatly affect its diagnostic value is still unclear. We await future studies to systematically assess the distribution of $\mathrm{L} / \mathrm{H}$ ratio in patients with CAD. Moreover, we only identified the diagnostic value of $\mathrm{L} / \mathrm{H}$ ratio and CCTA in patients with single-vessel disease. It is still unknown whether $\mathrm{L} / \mathrm{H}$ ratio could help improve CCTA's diagnostic accuracy in those with multi-vessel disease. Importantly, there is a designed observational cohort study, we only accessed the value of $\mathrm{L} / \mathrm{H}$ ratio or CCTA in plaque classification but not evaluate their property in predicting ACS. Prospective studies with following up are needed to further confirm the value of combination of $\mathrm{L} / \mathrm{H}$ ratio and CCTA before its use in the clinical settings.
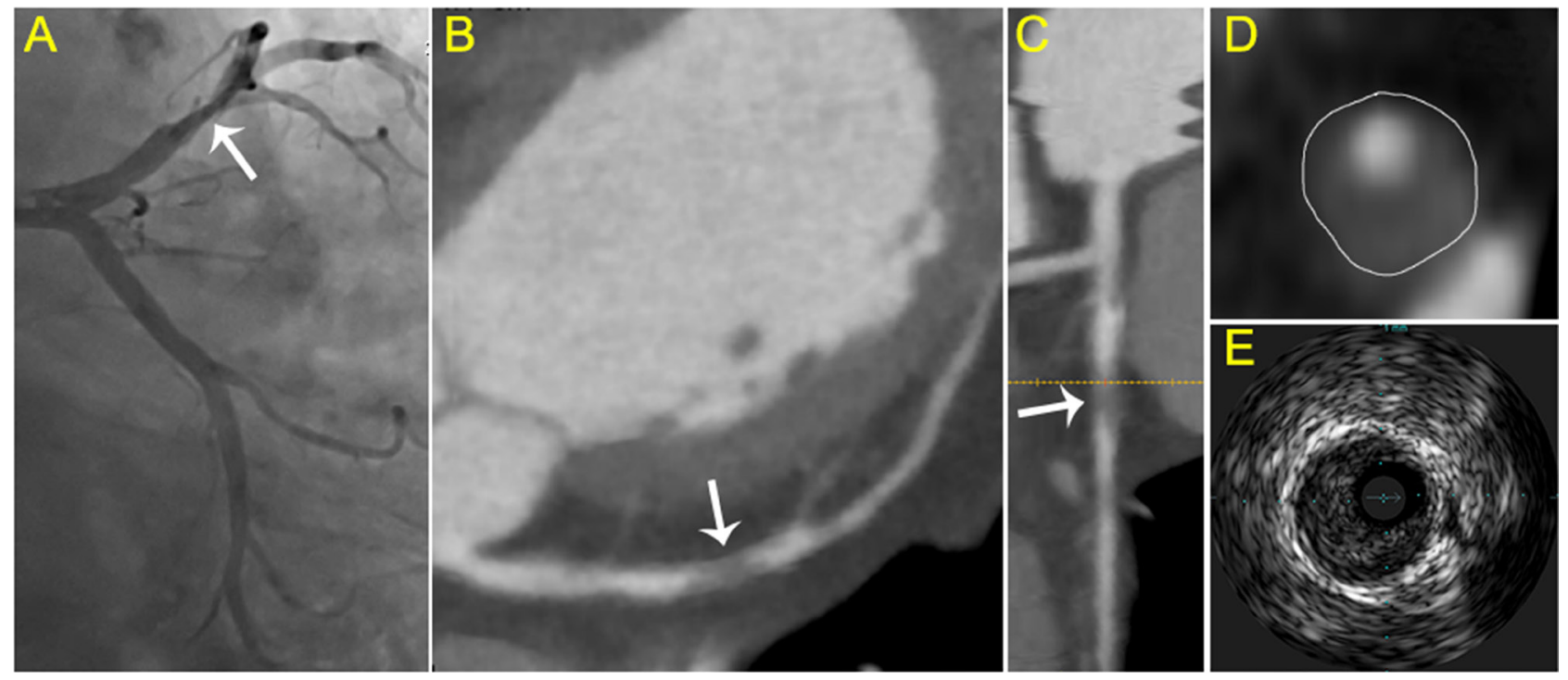

Figure 3: Typical visualization of soft plaque. (A) Angiography showed the culprit vessel in the proximal LCX. (B) axial view and (C) curved planar reformat of CCTA shows relevant plaque causing stenosis of the LCX (arrow). (D) cross-sectional view of soft plaque with low attenuation. (E) corresponding IVUS images. 


\section{MATERIALS AND METHODS}

\section{Study design and population}

From March 2014 to June 2016, patients admitted to the emergency department of Cangzhou Central Hospital were screened. They were matched for age, sex, body mass index (BMI), cardiovascular risks, and medications used. All the enrolled patients had blood collection, CCTA examination and IVUS imaging. Culprit lesion was determined during non-emergent invasive coronary angiography (ICA). Exclusion criteria of the study were (1) patients with multivessel disease (2) infectious endocarditis, congenital heart disease, cardiomyopathy, and primary valvular disease; (3) culprit lesion has implanted stent, had a history of coronary artery bypass grafting; (4) symptomatic peripheral vascular disease, thyroid disease, autoimmune disease, hematologic disease, malignant tumor or other severe disease; (5) did not complete the CCTA or IVUS imaging; (6) did not offer informed consent.

All subjects met the criteria were categorized into SAP group $(n=83)$ and ACS group $(n=129)$. The SAP group was classified based on the guidelines of the American College of Cardiology (ACC)/American Heart Association (AHA) [35]. Patients with single-vessel disease who were suggested to have elective PCI were enrolled in this study. These patients underwent CCTA
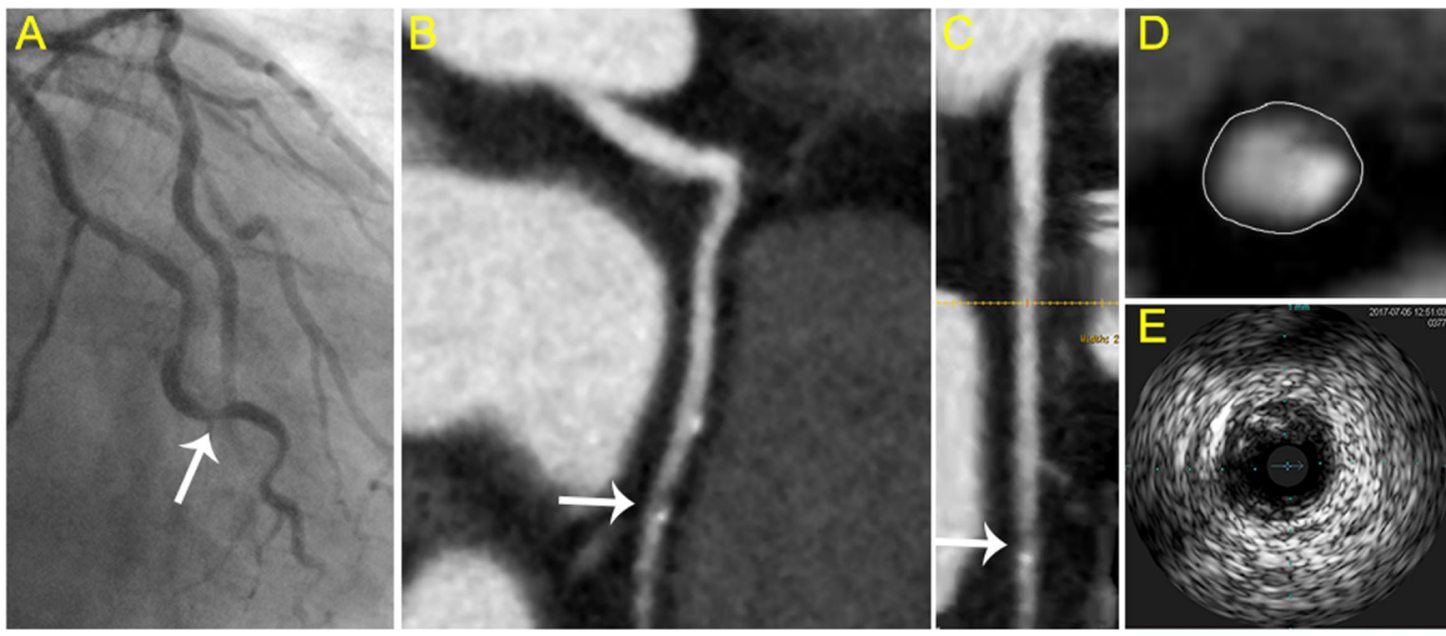

Figure 4: Typical visualization of mixed plaque. (A) Angiography showed the culprit vessel in the proximal LAD. (B) axial view and (C) curved planar reformat of CCTA shows relevant plaque of the LAD (arrow). (D) cross-sectional view of mixed plaque with eccentricity spotty calcification. (E) corresponding IVUS images.
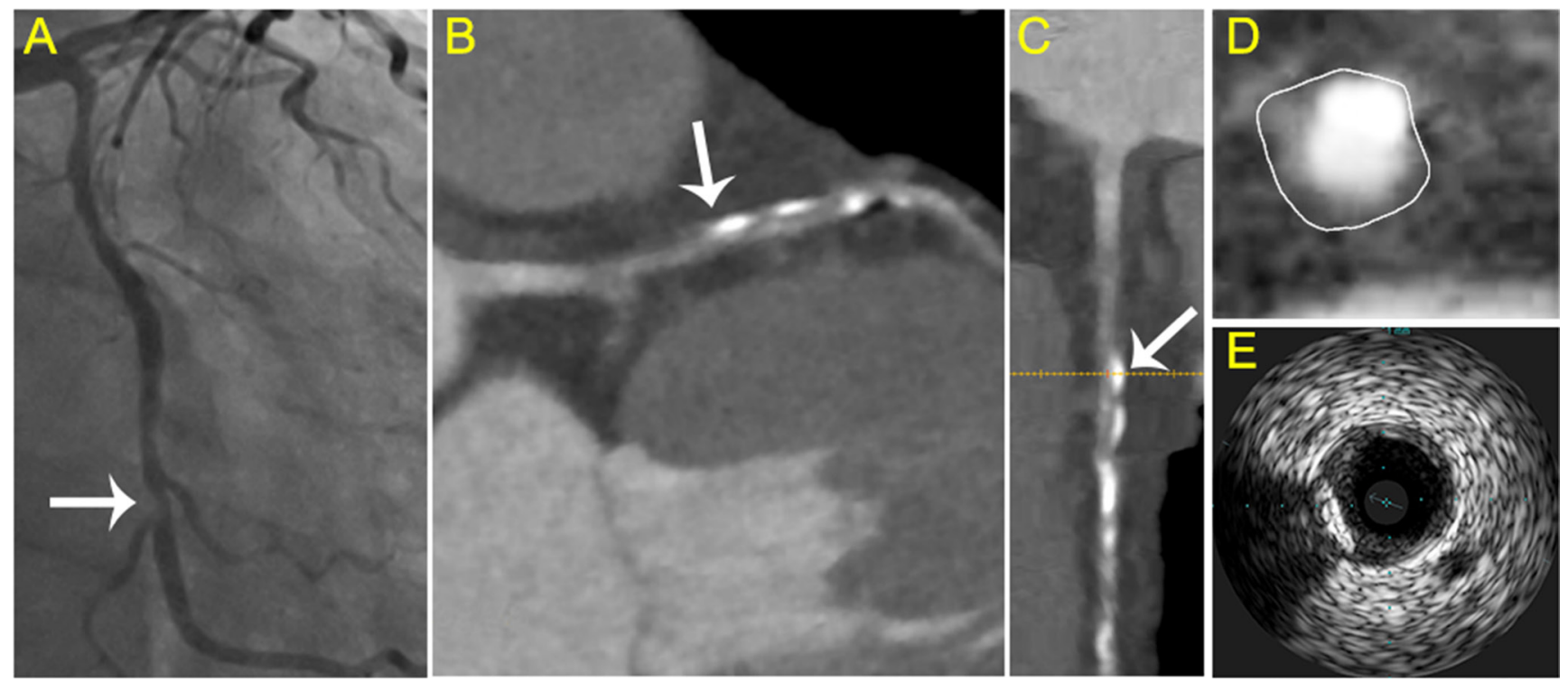

Figure 5: Typical visualization of calcified plaque. (A) Angiography revealed the culprit vessel in the middle LAD. (B) axial view and (C) curved planar reformat of CCTA shows relevant plaque of the LAD (arrow). (D) cross-sectional view of calcified plaque with calcification in the side portion. (E) corresponding IVUS images. 
examination before non-emergent ICA. Patients with ACS were identified in accordance with the guidelines of the ACC/AHA [36]. The ACS group included 43 patients with ST-segment elevation myocardial infarction (STEM), 60 patients with non-ST-segment elevation myocardial infarction (NSTEM), and 26 patients with unstable angina. High-risk patients admitted within $24 \mathrm{~h}$ after onset were excluded because these patients needed early ICA and PCI. Thereby, those presenting $24 \mathrm{~h}$ after onset of chest pain or intermediate- and low-risk patients were studied.

Finally, a total of 212 were admitted (Figure 1). The study was approved by the Research Ethics Committee of the Cangzhou Central Hospital, and informed consent was obtained from all individuals.

\section{Coronary computed tomographic angiography}

All subjects underwent CCTA before conventional invasive coronary angiography (ICA). We performed electrocardiographic-gated CTA using a 128-slice multi detector computed tomography CT scanner (Somatom Definition AS+; Siemens Medical Solutions, Forchheim, Germany) with a $2 \times 64 \times 0.6-\mathrm{mm}$ slice collimation, a gantry rotation time of $0.35 \mathrm{~s}$ and a tube voltage of 120 $\mathrm{kV}$, and the tube modulation was from 300 to $420 \mathrm{~mA}$, depending on the patient's height and weight. Patients with a heart rate of $\geq 60$ beats/min received $20 \mathrm{mg}$ of oral metoprolol $60 \mathrm{~min}$ before scanning and all patients received $0.3 \mathrm{mg}$ nitroglycerin sublingually before CT examination. Imaging was achieved using a contrast-enhanced ECG gating scanner. During CCTA acquisition, patients received $1.2 \mathrm{ml} / \mathrm{kg}$ body weight of iodinated contrast (Iohexol 350 $\mathrm{mg} \mathrm{I} / \mathrm{ml}$, GE Healthcare, UK) at a rate of $3.0 \mathrm{ml} / \mathrm{s}$ followed by $40 \mathrm{ml}$ saline solution at a rate of $3.0 \mathrm{ml} / \mathrm{s}$. The arterial phase was obtained with a delay time of $35 \mathrm{~s}$, portal venous phase with $70 \mathrm{~s}$ and equilibrium phase with $3 \mathrm{~min}$. The raw CT data were reconstructed using algorithms optimized for retrospective ECG-gated segment reconstruction with a $0.6-\mathrm{mm}$ slice thickness and a $0.3 \mathrm{~mm}$ increment. Other characteristics were previously described [37].

\section{Quantitative analysis of CCTA}

The target vessel was the culprit lesions. A cardiologist and a radiologist, who were blinded to the patients' clinical characteristics, analyzed the CCTA data, with maximum intensity and curved multiplanar reconstruction techniques. We calculated total calcium score and expressed as Agatston score [38]. A dedicated semi-automatic software prototype (Plaque Analysis 2.0.3 FRONTIER, Siemens) was used for the plaque analysis. All lesions with $\geq 25 \%$ stenosis on coronary CTA were evaluated. The start and end of a culprit lesion was defined as the proximal and distal non-diseased section with absence of atherosclerotic changes. CTA measures included lesion length, minimum lumen area (MLA), vessel volume, plaque volume, noncalcified plaque volume, and lumen volume. Plaque burden $\%=($ plaque area/vessel area $) \times 100$. The remodeling index was obtained by dividing the vessel diameter at the plaque site by the diameter at reference segment. Plaque morphology on CCTA was characterized as a) soft, b) mixed, c) calcified. Atheroma with density greater than 150 hounsfield unit (HU) and lesions with $50 \%$ or greater calcium was considered calcific plaque. Noncalcified plaques were subdivided into soft plaques with lipid core with a cutoff point of lower than $30 \mathrm{HU}$ and mixed plaques (30-150 HU) [39].

\section{Invasive coronary angiography and intravascular ultrasound}

Selective coronary angiography was performed in multipleorthogonal views using standard techniques within two weeks after CCTA and images were stored digitally. Angiograms were evaluated by two cardiologists blinded to both the purpose of the research and the subjects' CTA results. Angiographic plaque morphology, Thrombolysis In Myocardial Infarction (TIMI) grading, the severity of luminal stenosis were analyzed according to established invasive criteria $[40,41]$ and culprit lesions were confirmed according to $\mathrm{CAG}$, location of asynergy in Electrocardiograph, and location of ST-segment elevation in STEMI. When referring to $\mathrm{SAP}$, the lesions $>50 \%$, with the evidence of the subsequent IVUS, were defined as culprit lesions.

IVUS examination was performed after $200 \mu \mathrm{g}$ of intracoronary nitroglycerin immediately after guidewire crossing or dilation with a $1.5-$ to $2.5-\mathrm{mm}$ balloon, to examine the culprit lesion. The IVUS images were achieved using an iLab Ultrasound Imaging system (Boston Scientific Corp, Natick, MA, USA) and a 40 $\mathrm{MHz} 2.5 \mathrm{Fr}$ intravascular catheter. The catheter was advanced greater than $10 \mathrm{~mm}$ beyond the plaque, with the assistance of an automatic pullback device at $0.5 \mathrm{~mm} / \mathrm{s}$. Images were quantified for external elastic membrane area (EEM), lumen and plaque cross-sectional area and plaque volume. Volumes were calculated using Simpson's rule and also reported as normalized area (volume divided by length) [42]. Plaques were classified as a) soft, b) mixed, c) calcified, on the basis of the clinical expert consensus document on IVUS acquisition, measurement and reporting [43]. Soft plaque was defined as plaque tissue producing echogenicity less than that of the surrounding adventitia, in the absence of any calcium. mixed plaque was defined as atheroma having density equal or little more than to that of the adventitia without acoustic shadowing. Calcific plaque was defined as atheroma brighter than the adventitia with acoustic shadowing.

\section{Blood tests}

Blood samples were collected from all subjects prior to CCTA, the samples were drawn into tubes with ethylene diamine tetraacetic acid (EDTA) or sodium citrate and were 
separated by centrifugation at 3,000 rpm for 10 minutes within 2 hours. Then the samples were divided into three tubes, with immediate storage at $-80^{\circ} \mathrm{C}$ until analysis. ELECSYS 2010 automated analyser (Roche Diagnostics, Mannheim, Germany) was used to detect the level of hs-Tn T [44]. The level of D-dimer, NT-proBNP, Triglyceride, LDL, HDL, glycated hemoglobin (HbAlc), Serum creatinine (Scr), highsensitivity C-reactive protein (hs-CRP) and homocysteine (Hcy) were measured using a clinical automated biochemistry analyzer (Cobas6000; Roche Diagnostics).

\section{Statistical analysis}

The data were analyzed using SPSS version 22.0 (SPSS Inc., Chicago, IL, USA). Continuous variables were presented as medians \pm standard deviation and categorical variables were expressed as frequencies with percentages. The normality test of each variable was conducted by using the Kolmogorov-Smirnov test. Differences between groups were evaluated by Student's $t$-test or chi-square analysis. One-way analysis of variance (ANOVA) was used to compare the difference between more than two groups, and the differences between groups were subsequently determined by least significant difference (LSD) test when appropriate. A Kruskal-Wallis test was used for non-normally distributed data. Pearson's correlation coefficients were calculated between plaque volume, as well as Remodeling index, obtained from CCTA or IVUS. Patients were divided into groups according to the median of $\mathrm{L} / \mathrm{H}$ ratio (2.55). The sensitivity, specificity, PPV, $\mathrm{NPV}$, and diagnostic accuracy of $\mathrm{L} / \mathrm{H}$ ratio alone or in combination CCTA were calculated. Multivariable analysis was performed to determine independent predictors for $\mathrm{L} / \mathrm{H} \geq 2.5$ including age, BMI, hypertension, diabetes mellitus, triglyceride, HbAlc, Scr, hs-CRP, and Hcy. A $P$-value of $<0.05$ was considered statistically significant.

\section{CONCLUSIONS}

In conclusion, combined $\mathrm{L} / \mathrm{H}$ ratio and $\mathrm{CCTA}$ improves the diagnostic accuracy for noncalcified plaques as compared to CCTA along by using invasive IVUS as the reference standard. This has the potential to improve risk stratification and is useful for the subsequent treatment decisions.

\section{CONFLICTS OF INTEREST}

None.

\section{REFERENCES}

1. Libby P. Mechanisms of acute coronary syndromes and their implications for therapy. New England Journal of Medicine. 2013; 368:2004-13.
2. Mueller C, Hodgson JM, Schindler C, Perruchoud AP, Roskamm H, Buettner HJ. Cost-effectiveness of intracoronary ultrasound for percutaneous coronary interventions. Am J Cardiol. 2003; 91:143-7.

3. Thomsen C, Abdulla J. Characteristics of high-risk coronary plaques identified by computed tomographic angiography and associated prognosis: a systematic review and metaanalysis. Eur Heart J Cardiovasc Imaging. 2016; 17:120-9. https://doi.org/10.1093/ehjci/jev325.

4. Puchner SB, Liu T, Mayrhofer T, Truong QA, Lee H, Fleg JL, Nagurney JT, Udelson JE, Hoffmann U, Ferencik M. High-risk plaque detected on coronary CT angiography predicts acute coronary syndromes independent of significant stenosis in acute chest pain: results from the ROMICAT-II trial. J Am Coll Cardiol. 2014; 64:684-92. https://doi.org/10.1016/j.jacc.2014.05.039.

5. Sato A, Ohigashi H, Nozato T, Hikita H, Tamura M, Miyazaki S, Takahashi Y, Kuwahara T, Takahashi A, Hiroe M, Aonuma K. Coronary artery spatial distribution, morphology, and composition of nonculprit coronary plaques by 64-slice computed tomographic angiography in patients with acute myocardial infarction. Am J Cardiol. 2010; 105:930-5. https://doi.org/10.1016/j.amjcard.2009.11.028.

6. Achenbach S, Ropers D, Hoffmann U, MacNeill B, Baum U, Pohle K, Brady TJ, Pomerantsev E, Ludwig J, Flachskampf FA, Wicky S, Jang IK, Daniel WG. Assessment of coronary remodeling in stenotic and nonstenotic coronary atherosclerotic lesions by multidetector spiral computed tomography. J Am Coll Cardiol. 2004; 43:842-7. https:// doi.org/10.1016/j.jacc.2003.09.053.

7. Marwan M, Taher MA, El Meniawy K, Awadallah H, Pflederer T, Schuhback A, Ropers D, Daniel WG, Achenbach S. In vivo CT detection of lipid-rich coronary artery atherosclerotic plaques using quantitative histogram analysis: a head to head comparison with IVUS. Atherosclerosis. 2011; 215:110-5. https://doi.org/10.1016/j.atherosclerosis.2010.12.006.

8. Pundziute G, Schuijf JD, Jukema JW, Decramer I, Sarno G, Vanhoenacker PK, Reiber JH, Schalij MJ, Wijns W, Bax JJ. Head-to-head comparison of coronary plaque evaluation between multislice computed tomography and intravascular ultrasound radiofrequency data analysis. JACC Cardiovasc Interv. 2008; 1:176-82. https://doi.org/10.1016/j. jcin.2008.01.007.

9. Kesarwani M, Nakanishi R, Choi TY, Shavelle DM, Budoff MJ. Evaluation of Plaque Morphology by 64-Slice Coronary Computed Tomographic Angiography Compared to Intravascular Ultrasound in Nonocclusive Segments of Coronary Arteries. Acad Radiol. 2017; 24:968-974. https:// doi.org/10.1016/j.acra.2017.03.001.

10. Pohle K, Achenbach S, Macneill B, Ropers D, Ferencik M, Moselewski F, Hoffmann U, Brady TJ, Jang IK, Daniel WG. Characterization of non-calcified coronary atherosclerotic plaque by multi-detector row CT: comparison to IVUS. Atherosclerosis. 2007; 190:174-80. https://doi.org/10.1016/j.atherosclerosis.2006.01.013. 
11. Seifarth H, Schlett CL, Lehman SJ, Bamberg F, Donnelly P, Januzzi JL, Koenig W, Truong QA, Hoffmann U. Correlation of concentrations of high-sensitivity troponin $\mathrm{T}$ and high-sensitivity C-reactive protein with plaque progression as measured by CT coronary angiography. J Cardiovasc Comput Tomogr. 2014; 8:452-8. https://doi.org/10.1016/j.jcct.2014.09.005.

12. Rusnak J, Behnes M, Reckord N, Hoffmann U, Natale M, Hoffmann J, Weidner K, Lang S, Mukherji A, Kruska M, Henzler T, Schoenberg SO, Borggrefe M, et al. High Sensitivity Troponins Discriminate Different Morphologies of Coronary Artery Plaques Being Assessed by Coronary Computed Tomography Angiography. Dis Markers. 2017; 2017:9306409. https://doi.org/10.1155/2017/9306409.

13. Reckord N, Natale M, Mukherji A, Rusnak J, Ansari U, Henzler T, Hoffmann U, Borggrefe M, Mashayekhi K, Bertsch T, Akin I. High Sensitivity Troponin I and T reflect the presence of Obstructive and Multi-Vessel Coronary Artery Disease being assessed by Coronary Computed Tomography Angiography. Curr Pharm Biotechnol. 2017; 18:508-515. https://doi.org/10.2174/1389201018666170601082145.

14. Altintas S, Cardinaels EP, Versteylen MO, Joosen IA, Seifert M, Wildberger JE, Crijns HJ, Nelemans PJ, Van Dieijen-Visser MP, Mingels AM, Das M, Kietselaer BL. Unstable coronary plaque characteristics are associated with high-sensitivity cardiac troponin $\mathrm{T}$ and $\mathrm{N}$-terminal ProBrain Natriuretic Peptide. J Cardiovasc Comput Tomogr. 2016; 10:82-8. https://doi.org/10.1016/j.jcct.2015.10.001.

15. Wen Y, Xia D, Wang Y, Zhang H, Li H, Ali G, Gao Y, Li J, Sun W, Li L. Cystatin C is Associated With Plaque Phenotype and Plaque Burden. Kidney Blood Press Res. 2016; 41:197-207. https://doi.org/10.1159/000443422.

16. Gu C, Wang F, Hou Z, Lv B, Wang Y, Cong X, Chen X. Sex-related differences in serum matrix metalloproteinase-9 screening non-calcified and mixed coronary atherosclerotic plaques in outpatients with chest pain. Heart Vessels. 2017; 32:1424-1431.https://doi.org/10.1007/s00380-017-1014-3.

17. Dohi T, Miyauchi K, Okazaki S, Yokoyama T, Ohkawa R, Nakamura K, Yanagisawa N, Tsuboi S, Ogita M, Yokoyama K, Kurata T, Yatomi Y, Daida H. Decreased circulating lipoprotein-associated phospholipase A2 levels are associated with coronary plaque regression in patients with acute coronary syndrome. Atherosclerosis. 2011; 219:90712. https://doi.org/10.1016/j.atherosclerosis.2011.09.019.

18. Kawakami R, Matsumoto I, Shiomi M, Kurozumi M, Miyake Y, Ishizawa M, Ishikawa K, Murakami K, Noma T, Takagi Y, Nishimoto N, Minamino T. Role of the LowDensity Lipoprotein-Cholesterol/High-Density LipoproteinCholesterol Ratio in Predicting Serial Changes in the Lipid Component of Coronary Plaque. Circ J. 2017; 81:1439-1446. https://doi.org/10.1253/circj.CJ-16-1209.

19. Kitagawa T, Yamamoto H, Horiguchi J, Ohashi N, Kunita E, Utsunomiya H, Kihara Y. Effects of statin therapy on non-calcified coronary plaque assessed by 64-slice computed tomography. Int J Cardiol. 2011; 150:146-50. https://doi.org/10.1016/j.ijcard.2010.03.005.
20. Boogers MJ, Broersen A, van Velzen JE, de Graaf FR, El-Naggar HM, Kitslaar PH, Dijkstra J, Delgado V, Boersma E, de Roos A, Schuijf JD, Schalij MJ, Reiber JH, et al. Automated quantification of coronary plaque with computed tomography: comparison with intravascular ultrasound using a dedicated registration algorithm for fusion-based quantification. Eur Heart J. 2012; 33:1007-16. https://doi.org/10.1093/eurheartj/ehr465.

21. Leschka S, Seitun S, Dettmer M, Baumuller S, Stolzmann P, Goetti R, Scheffel H, Feuchtner G, Wunnicke K, Wildermuth S, Oehlschlegel C, Marincek B, Jochum W, et al. Ex vivo evaluation of coronary atherosclerotic plaques: characterization with dual-source CT in comparison with histopathology. J Cardiovasc Comput Tomogr. 2010; 4:3018. https://doi.org/10.1016/j.jcct.2010.05.016.

22. Hong MK, Mintz GS, Lee CW, Lee JW, Park JH, Park DW, Lee SW, Kim YH, Cheong SS, Kim JJ, Park SW, Park SJ. A three-vessel virtual histology intravascular ultrasound analysis of frequency and distribution of thin-cap fibroatheromas in patients with acute coronary syndrome or stable angina pectoris. Am J Cardiol. 2008; 101:568-72. https://doi.org/10.1016/j.amjcard.2007.09.113.

23. Leber AW, Becker A, Knez A, von Ziegler F, Sirol M, Nikolaou K, Ohnesorge B, Fayad ZA, Becker CR, Reiser M, Steinbeck G, Boekstegers P. Accuracy of 64-slice computed tomography to classify and quantify plaque volumes in the proximal coronary system: a comparative study using intravascular ultrasound. J Am Coll Cardiol. 2006; 47:672-7. https://doi.org/10.1016/j.jacc.2005.10.058.

24. Voros S, Rinehart S, Qian Z, Joshi P, Vazquez G, Fischer C, Belur P, Hulten E, Villines TC. Coronary atherosclerosis imaging by coronary CT angiography: current status, correlation with intravascular interrogation and metaanalysis. JACC Cardiovasc Imaging. 2011; 4:537-48. https://doi.org/10.1016/j.jcmg.2011.03.006.

25. Gao D, Ning N, Guo Y, Ning W, Niu X, Yang J. Computed tomography for detecting coronary artery plaques: a metaanalysis. Atherosclerosis. 2011; 219:603-9. https://doi. org/10.1016/j.atherosclerosis.2011.08.022.

26. Maurovich-Horvat P, Schlett CL, Alkadhi H, Nakano M, Otsuka F, Stolzmann P, Scheffel H, Ferencik M, Kriegel MF, Seifarth H, Virmani R, Hoffmann U. The napkin-ring sign indicates advanced atherosclerotic lesions in coronary CT angiography. JACC Cardiovasc Imaging. 2012; 5:124352. https://doi.org/10.1016/j.jcmg.2012.03.019.

27. Achenbach S. Can CT detect the vulnerable coronary plaque? Int J Cardiovasc Imaging. 2008; 24:311-2. https:// doi.org/10.1007/s10554-007-9281-1.

28. Okada K, Hibi K, Gohbara M, Kataoka S, Takano K, Akiyama E, Matsuzawa Y, Saka K, Maejima N, Endo M, Iwahashi N, Tsukahara K, Kosuge M, et al. Association between blood glucose variability and coronary plaque instability in patients with acute coronary syndromes. Cardiovasc Diabetol. 2015; 14:111. https://doi.org/10.1186/ s12933-015-0275-3. 
29. Packard CJ, Ford I, Robertson M, Shepherd J, Blauw GJ, Murphy MB, Bollen EL, Buckley BM, Cobbe SM, Gaw A, Hyland M, Jukema JW, Kamper AM, et al. Plasma lipoproteins and apolipoproteins as predictors of cardiovascular risk and treatment benefit in the PROspective Study of Pravastatin in the Elderly at Risk (PROSPER). Circulation. 2005; 112:3058 65. https://doi.org/10.1161/circulationaha.104.526848.

30. Nicholls SJ, Tuzcu EM, Sipahi I, Grasso AW, Schoenhagen P, Hu T, Wolski K, Crowe T, Desai MY, Hazen SL, Kapadia SR, Nissen SE. Statins, high-density lipoprotein cholesterol, and regression of coronary atherosclerosis. Jama. 2007; 297:499-508. https://doi.org/10.1001/jama.297.5.499.

31. Kurebayashi N, Yoshikawa D, Ishii H, Sato B, Ando H, Okada T, Hayakawa S, Okumura N, Isobe S, Takeshita K, Hayashi M, Uetani T, Amano T, et al. Impact of the low- to high-density lipoprotein cholesterol ratio on composition of angiographically ambiguous left main coronary artery plaque. Circ J. 2011; 75:1960-7.

32. Kim JH, Jeong MH, Hong YJ, Lee KH, Kim IS, Choi YH, Lee MG, Park KH, Sim DS, Kim JH, Ahn Y, Cho JG, Park JC, et al. Low density lipoprotein-cholesterol/high density lipoprotein-cholesterol ratio predicts plaque vulnerability in patients with stable angina. Korean Circ J. 2012; 42:24651. https://doi.org/10.4070/kcj.2012.42.4.246.

33. Hiro T, Kimura T, Morimoto T, Miyauchi K, Nakagawa Y, Yamagishi M, Ozaki Y, Kimura K, Saito S, Yamaguchi T, Daida H, Matsuzaki M. Effect of intensive statin therapy on regression of coronary atherosclerosis in patients with acute coronary syndrome: a multicenter randomized trial evaluated by volumetric intravascular ultrasound using pitavastatin versus atorvastatin (JAPAN-ACS [Japan assessment of pitavastatin and atorvastatin in acute coronary syndrome] study). J Am Coll Cardiol. 2009; 54:293-302. https://doi.org/10.1016/j.jacc.2009.04.033.

34. Tani S, Nagao K, Hirayama A. HMG-CoA reductase inhibitor (Statin) therapy and coronary atherosclerosis in Japanese subjects: role of high-density lipoprotein cholesterol. Am J Cardiovasc Drugs. 2011; 11:411-7. https://doi.org/10.2165/11594620-000000000-00000.

35. Fihn SD, Blankenship JC, Alexander KP, Bittl JA, Byrne JG, Fletcher BJ, Fonarow GC, Lange RA, Levine GN, Maddox TM, Naidu SS, Ohman EM, Smith PK. 2014 ACC/AHA/AATS/ PCNA/SCAI/STS focused update of the guideline for the diagnosis and management of patients with stable ischemic heart disease: a report of the American College of Cardiology/American Heart Association Task Force on Practice Guidelines, and the American Association for Thoracic Surgery, Preventive Cardiovascular Nurses Association, Society for Cardiovascular Angiography and Interventions, and Society of Thoracic Surgeons. Circulation. 2014; 130:1749-67. https://doi.org/10.1161/cir.0000000000000095.

36. Wright RS, Anderson JL, Adams CD, Bridges CR, Casey DE Jr, Ettinger SM, Fesmire FM, Ganiats TG, Jneid H, Lincoff AM, Peterson ED, Philippides GJ, Theroux P, et al. 2011 ACCF/ AHA focused update of the Guidelines for the Management of Patients with Unstable Angina/Non-ST-Elevation Myocardial
Infarction (updating the 2007 guideline): a report of the American College of Cardiology Foundation/American Heart Association Task Force on Practice Guidelines developed in collaboration with the American College of Emergency Physicians, Society for Cardiovascular Angiography and Interventions, and Society of Thoracic Surgeons. J Am Coll Cardiol. 2011; 57:1920-59. https://doi.org/10.1016/j. jacc.2011.02.009.

37. Nieman K, Galema T, Weustink A, Neefjes L, Moelker A, Musters P, de Visser R, Mollet N, Boersma H, de Feijter PJ. Computed tomography versus exercise electrocardiography in patients with stable chest complaints: real-world experiences from a fast-track chest pain clinic. Heart. 2009; 95:1669-75. https://doi.org/10.1136/hrt.2009.169441.

38. Agatston AS, Janowitz WR, Hildner FJ, Zusmer NR, Viamonte M Jr, Detrano R. Quantification of coronary artery calcium using ultrafast computed tomography. J Am Coll Cardiol. 1990; 15:827-32.

39. Motoyama S, Kondo T, Sarai M, Sugiura A, Harigaya H, Sato T, Inoue K, Okumura M, Ishii J, Anno H, Virmani R, Ozaki Y, Hishida H, et al. Multislice computed tomographic characteristics of coronary lesions in acute coronary syndromes. J Am Coll Cardiol. 2007; 50:319-26. https:// doi.org/10.1016/j.jacc.2007.03.044.

40. Goldstein JA, Demetriou D, Grines CL, Pica M, Shoukfeh M, O'Neill WW. Multiple complex coronary plaques in patients with acute myocardial infarction. $\mathrm{N}$ Engl J Med. 2000; 343:915-22. https://doi.org/10.1056/ nejm200009283431303.

41. Yamamoto MH, Maehara A, Poon M, Guo J, Yamashita K, Yakushiji T, Saito S, Koyama K, Mintz GS, Ochiai M. Morphological assessment of chronic total occlusions by combined coronary computed tomographic angiography and intravascular ultrasound imaging. Eur Heart J Cardiovasc Imaging. 2017; 18:315-22. https://doi.org/10.1093/ehjci/jew077.

42. Yun KH, Mintz GS, Witzenbichler B, Inaba S, Shimizu T, Metzger DC, Rinaldi MJ, Mazzaferri EL Jr, Duffy PL, Weisz G, Stuckey TD, Brodie BR, Kirtane AJ, et al. Relationship Between Platelet Reactivity and Culprit Lesion Morphology: An Assessment From the ADAPT-DES Intravascular Ultrasound Substudy. JACC Cardiovasc Imaging. 2016; 9:849-54. https://doi.org/10.1016/j.jcmg.2015.08.019.

43. American College of Cardiology Clinical Expert Consensus Document on Standards for Acquisition, Measurement and Reporting of Intravascular Ultrasound Studies (IVUS). A report of the American College of Cardiology Task Force on Clinical Expert Consensus Documents developed in collaboration with the European Society of Cardiology endorsed by the Society of Cardiac Angiography and Interventions. Eur J Echocardiogr. 2001; 2:299-313.

44. Thygesen K, Mair J, Giannitsis E, Mueller C, Lindahl B, Blankenberg S, Huber K, Plebani M, Biasucci LM, Tubaro M, Collinson P, Venge P, Hasin Y, et al. How to use highsensitivity cardiac troponins in acute cardiac care. European Heart Journal. 2012; 33:2252. 